\title{
Development of TUA-WELLNESS screening tool for screening risk of mild cognitive impairment among community-dwelling older adults
}

\author{
Divya Vanoh' \\ Suzana Shahar' \\ Razali Rosdinom ${ }^{2}$ \\ Normah Che Din ${ }^{3}$ \\ Hanis Mastura Yahya ${ }^{4}$ \\ Azahadi Omar ${ }^{5}$ \\ 'Dietetic Programme, Centre of \\ Healthcare Sciences, Faculty of Health \\ Sciences, Universiti Kebangsaan \\ Malaysia, Kuala Lumpur, Malaysia; \\ ${ }^{2}$ Department of Psychiatry, University \\ Kebangsaan Medical Centre, Kuala \\ Lumpur, Malaysia; ${ }^{3} \mathrm{Health}$ Psychology \\ Programme, ${ }^{4}$ Nutrition Programme, \\ Faculty of Health Sciences, Universiti \\ Kebangsaan Malaysia, Kuala Lumpur, \\ Malaysia; ${ }^{5}$ nstitute of Public Health, \\ Ministry of Health, Kuala Lumpur, \\ Malaysia
}

This article was published in the following Dove Press journal:

Clinical Interventions in Aging

9 May 2016

Number of times this article has been viewed
Background and aim: Focus on screening for cognitive impairment has to be given particular importance because of the rising older adult population. Thus, this study aimed to develop and assess a brief screening tool consisting of ten items that can be self-administered by community dwelling older adults (TUA-WELLNESS).

Methodology: A total of 1,993 noninstitutionalized respondents aged 60 years and above were selected for this study. The dependent variable was mild cognitive impairment (MCI) assessed using neuropsychological test batteries. The items for the screening tool comprised a wide range of factors that were chosen mainly from the analysis of ordinal logistic regression (OLR) and based on past literature. A suitable cut-off point was developed using receiver operating characteristic analysis.

Results: A total of ten items were included in the screening tool. From the ten items, eight were found to be significant by ordinal logistic regression and the remaining two items were part of the tool because they showed strong association with cognitive impairment in previous studies. The area under curve (AUC), sensitivity, and specificity for cut-off 11 were $0.84 \%$, $83.3 \%$, and $73.4 \%$, respectively.

Conclusion: TUA-WELLNESS screening tool has been used to screen for major risk factors of MCI among Malaysian older adults. This tool is only suitable for basic MCI risk screening purpose and should not be used for diagnostic purpose.

Keywords: mild cognitive impairment, screening, sensitivity, specificity, TUA-WELLNESS

\section{Introduction}

Mild cognitive impairment (MCI) is a condition encompassing clinical, functional, and cognitive criteria. ${ }^{1}$ Unlike dementia, MCI is reversible if early intervention strategies are taken to tackle the problem. ${ }^{2}$ With the expanding aging population, the prevalence of comorbidities and functional disabilities have risen tremendously. These have affected the quality of life of older adults, and thus contributed to cognitive decline. ${ }^{3,4}$ Since MCI is reversible, preventive strategies have to be focused to reduce overall health care cost. A recent review has listed hypertension, diabetes mellitus, hyperlipidemia, physical activity, smoking, and alcohol as modifiable risk factors of MCI. ${ }^{5}$ Brain training activities, such as computer games and Sudoku, have shown activations in several brain regions among subjects with $\mathrm{MCI} .{ }^{6} \mathrm{~A}$ diet rich in fruits, vegetables, whole grain, and low in red meat has been shown to be protective against cognitive decline. ${ }^{7}$

Focus on screening for cognitive impairment has to be given particular importance with the rising geriatric population. However, to date, there is no evidence of a single best screening tool in detecting MCI. ${ }^{8}$ Nishiwaki et $\mathrm{al}^{9}$ have reported that
Correspondence: Suzana Shahar Dietetic Programme, Department of Nutrition and Dietetic, Faculty of Healthcare Sciences, 50300 Kuala Lumpur, Malaysia

Tel +60 392897687

Email suzana.shahar@ukm.edu.my (c) (1) (2) 2016 Vanoh et al. This work is published and licensed by Dove Medical Press Limited. The full terms of this license are available at https://www.dovepress.com/terms.php
and incorporate the Creative Commons Attribution - Non Commercial (unported, v3.0) License (http://creativecommons.org/licenses/by-nc/3.0/). By accessing the work you BV NC and incorporate the Creative Commons Attribution - Non Commercial (unported, v3.0) License (http://creativecommons.org/licenses/by-nd/3.0/). By accessing the work you
hereby accept the Terms. Non-commercial uses of the work are permitted without any further permission from Dove Medical Press Limited, provided the work is properly attributed. For permission for commercial use of this work, please see paragraphs 4.2 and 5 of our Terms (https://www.dovepress.com/terms.php). 
Clock Drawing Test (CDT) was not a suitable screening tool for MCI, but more appropriate for moderate-to-severe cognitive impairment. On the other hand, Mini Mental State Examination (MMSE) is widely used for screening of global function. However, MMSE has certain limitations such as educational/language/cultural bias, requires an interviewer to provide scoring, and only includes items that measure cognitive functions. ${ }^{10}$ Besides, MMSE cut-off points vary according to population. There is no comprehensive screening tool that measures other risk factors of cognitive impairment such as comorbidities, diet, lifestyle, quality of life, and practice of calorie restriction. As such, there is a need for the development of a screening tool that incorporates potential population-specific risk factors of $\mathrm{MCI}$.

Screening for MCI is essential as new drugs for early treatment are currently available. There are very limited self-administered screening tools for detecting cognitive impairment and MCI in the community, with a very small proportion rated highly for both validity and content. ${ }^{8}$ More recently, a self-reported screening tool known as Alzheimer's Disease Risk Index, for usage in a population, has been developed to identify risk of dementia but not MCI. ${ }^{11}$ Hence, this study aimed to develop a rapid screening tool, known as TUA-WELLNESS, to identify individuals at risk of MCI in the population. This study was part of a large-scale study to develop a neuroprotective model for healthy longevity among Malaysian elderly. Neuroprotective model comprises of wide range of factors leading to cognitive decline, which are identified through thorough biophysical health, dietary, and lifestyle assessment.

\section{Methodology}

As mentioned earlier, this study was part of the "Towards Useful Aging" (TUA) longitudinal study, which enrolled 1,993 subjects (1,002 men and 991 women) selected from four states in Malaysia, namely, Johor, Selangor, Perak, and Kelantan. Selection of respondents for this study was done in collaboration with the Department of Statistics, Malaysia, using a multistage random sampling method. This involved three stages; primary sampling unit (PSU), secondary sampling unit (SSU), and tertiary sampling unit (TSU). PSU was done to divide Malaysia into four main regions (north, south, east, and central) and select one state from each region based on which one had the highest number of older adults. This was followed by SSU, which involved the formation of census circle (CC) for each selected state. $\mathrm{CC}$ was selected by the Department of Statistics based on criteria that at least $10 \%$ of the geriatric population resides in the CC. Finally, TSU was the process of choosing living quarters from each CC. Older adults who met the inclusion criteria were chosen as respondents for this study.

A home visit was conducted to inform potential respondents about the upcoming health screening program. Signed inform consent was obtained if respondents were willing to participate in this study. Consent was taken in the form of thumb print for subjects who were illiterate. Subjects were reminded about the program via phone call. They were required to fast overnight for blood withdrawal and body composition measurement. Research was conducted by several trained enumerators. A validated questionnaire was used to obtain information on sociodemography, psychosocial, dietary intake, anthropometry, body composition, fitness, functional status, depression, quality of life, cognitive function, and lifestyle characteristics using an interview-based approach carried out by trained field-workers. This study was for a duration of 1 year (from 2013 to 2014) and had a good participation rate of $88 \%$.

This study only included subjects with at least moderate cognitive impairment. On the basis of Clinical Practice Guidelines of Dementia, moderate cognitive impairment for Malaysian population was indicated by MMSE score of 15 and above. MMSE below 15 was considered severe cognitive impairment and may be indicative of dementia. ${ }^{12}$ Inclusion criteria were older adults aged 60 years and above with no dementia (dementia was diagnosed by the doctor). Meanwhile, exclusion criteria were bed-ridden or wheelchair-bound older adults and those with severe psychiatric problems. Respondents of this study were communitydwelling subjects who were not institutionalized. This study was performed after obtaining ethical approval from Medical Research Ethics Committee of Research University Kebangsaan Malaysia.

\section{Assessment of neurocognitive status}

Neurocognitive status was the dependent variable in this study, and it consisted of three categories, namely, successful aging (SA), usual aging (UA), and MCI. SA was defined as being free from six chronic diseases (diabetes, hypertension, chronic lung diseases, cancer, heart diseases, and stroke) and having normal global function was assessed using MiniMental State Examination, excellent quality of life, good self-rated health, and no functional limitations (measured using activities of daily living and instrumental activities of daily living). ${ }^{13,14}$ On the other hand, respondents were reported to have MCI if they met the MCI criteria proposed by Petersen et $\mathrm{al}^{15}$ and Lee et al: ${ }^{16}$ the absence of dementia (diagnosed 
by doctor), subjective cognitive impairment (obtained from subjects or caregiver), objective memory impairment (scoring at least 1.5 standard deviation [SD] below the mean for at least one of the cognitive tests), very minimal or no functional limitations (measured using activities of daily living and instrumental activities of daily living), and having normal global function. Participants who failed to meet the criteria for SA and MCI were in the category of UA.

\section{Questionnaires}

Sociodemography information included age, sex, ethnicity, marital status, employment status, total monthly and household income, living arrangement, education years, literacy status, current income satisfaction, and economic hardship. Several comorbidities were assessed, namely, diabetes, hypertension, hyperlipidemia, heart diseases, stroke, constipation, osteoarthritis, cancer, cataract/glaucoma, and urinary incontinence. Blood was taken for fasting blood sugar evaluation.

Cognitive function was assessed using MMSE for global function, ${ }^{17}$ Digit Span for working memory and attention, ${ }^{18}$ and Rey Auditory Verbal Learning Test (RAVLT) for verbal memory. ${ }^{19}$ Furthermore, level of social support was determined using Medical Outcomes Study (MOS) social support survey ${ }^{20}$ and Lubben Social Network Scale-6. ${ }^{21}$ MOS was a 19-item questionnaire that measured various dimensions of social support, namely, tangible support, emotional/informational support, affective support, and positive social interaction. The Cronbach's alpha value for MOS was 0.97. Lubben Social Network Scale-6 consisted of six items, which screened for social isolation. Neuroticism was identified using neuroticism subscale of Eysenck Personality Questionnaire-Revised, which consisted of 12 items. ${ }^{22} \mathrm{Neu}-$ roticism was the personality trait of extreme negative emotions such as depression, anxiety, and moodiness.

Besides, disability was assessed using WHODAS 2.0 and captures six major domains, namely, self-care, participation, cognition, mobility, getting along, and life activities. ${ }^{23}$ Quality of life was a single question that required respondents to rate their current quality of life as either "very satisfied", "satisfied", "not satisfied", or "not satisfied at all". Self-rated health consisted of five options, namely, "I am well most of the time", "I am well some of the time", "I am not well some of the time", "I am not well most of the time", and "I am ill most of the time".

Meanwhile, Victoria Longitudinal Study-Activity Lifestyle Questionnaire was used to determine the participation of older adults in physical, mental, and social activities. ${ }^{24}$
The original 70-item questionnaire was reduced by factorial analysis to 26 items, with Cronbach's $\alpha$ of 0.66 . Examples of physical lifestyle activities were exercising, doing housework, and recreation. Mental lifestyle tasks involved performing simple technical activities such as changing bulb or repairing tap leakage, and using modern gadgets. Besides that, social lifestyle activities included going for shopping or eating out with family members.

Respondents were also exposed to several fitness tests, under the supervision of a trained physiotherapist. Among the fitness tests were 2-minute step test, timed up and go, chair stand test, chair sit and reach test, hand grip, and back scratch test. Nutritional status was assessed using body mass index and metabolic syndrome. Based on body mass index, subjects were categorized as underweight $\left(<18.5 \mathrm{~kg} / \mathrm{m}^{2}\right)$, normal (18.5-24.9 kg/m²), overweight (25.0-29.9 kg/m²), and obese $\left(30.0 \mathrm{~kg} / \mathrm{m}^{2}\right) .{ }^{25}$ Metabolic syndrome was measured using International Diabetes Federation criteria. ${ }^{26}$ Besides that, intake of fresh fruits, fresh fruit juices, and vegetables were also evaluated using Diet History Questionnaire. ${ }^{27}$ Practice of caloric restriction among older adults was assessed by asking them if they practice "Sunnah" fasting (fasting every Monday and Thursday by the Muslims), vegetarianism, or restrict intake of certain foods during certain religious occasion.

\section{Development of screening tool}

Several factors were taken into consideration during the development of screening tool, namely, use of simple language, short sentences, and tools that can be self-administered by older adults. Selection of variables for the screening tool was based on literature of the risk factors associated with MCI.

\section{Statistical analysis}

Several statistical analyses were employed in this study. Details of the analyses are reported in each of the following sections.

\section{Determination of ten items for TUA-WELLNESS screening tool}

A total of 1,993 respondents were involved in the study to identify the items for the screening tool. Selection of questions related to cognitive decline was done in two phases. The first phase was the univariable analysis between the parameters and neurocognitive status (SA, UA, and MCI) using Pearson $\chi^{2}$ for categorical variables and one-way between-group ANOVA for numerical variables. Factors with significant $P$-value (less than 0.05 ) were entered into the multivariate model. 
The second phase was the ordinal logistic regression (OLR) carried out between all the significant variables in the first phase with neurocognitive status as the dependent variable. OLR was chosen because the dependent variable (neurocognitive status) had three categories. Reference variable for the OLR model was the group with normal cognitive function, which was SA. The coding for the dependent variable was 0 (SA), 1 (UA), and 2 (MCI). Thus, any significant variables from this OLR model were the predictors of cognitive decline. OLR was employed in a stepwise manner due to the presence of numerous variables in this study. Seven different OLR models were created, and the details of each model were as follows:

\section{Model I}

Sociodemography model, which consisted of age, monthly income, sex, ethnicity, years of education, literacy status (either literate or illiterate), current income satisfaction, and economic hardship.

\section{Model 2}

Comorbidities model, which consisted of fasting blood sugar, systolic blood pressure, hyperlipidemia, diabetes, heart diseases, stroke, chronic lung diseases, cancer, constipation, cataract or glaucoma, osteoarthritis, and urinary incontinence.

\section{Model 3}

Fitness, nutritional, and functional status model, which consisted of percentage body fat, fat free mass, disability, metabolic syndrome, abdominal obesity, score from hand grip, 2-minute step test, chair stand test, chair sit and reach test, timed up and go test, and back scratch test.

\section{Model 4}

Psychosocial, which consisted of tangible support, affective support, total social support, social isolation, neuroticism, health and life satisfaction, and capability of sexual relationship with spouse.

\section{Model 5}

Dietary intake and practice, which consisted of consumption of fresh fruits or fresh fruit juices, intake of eicosapentanoic acid, and docosahexanoic acid as well as practice of calorie restriction.

\section{Model 6}

Lifestyle model, which consisted of total score for mental lifestyle task, and participation in physical activities (either regular or not active).

\section{Model 7}

Final model, which consisted of intake of fresh fruits or fresh fruit juices, score from timed up and go test, total score for mental lifestyle task, education years, systolic blood pressure, intake of docosahexanoic acid, tangible support, disability, fasting blood sugar, hyperlipidemia, diabetes, chronic lung diseases, cancer, heart diseases, stroke, quality of life, self-rated health, caloric restriction through "Sunnah" fasting or practicing vegetarianism, capability of having sex, participation in physical activity, use of modern gadgets, and performing simple mechanical-based task.

From the OLR model, eight risk factors were significant and were selected as items of TUA-WELLNESS. However, several other factors such as quality of life, self-rated health status, intake of vegetables, and the presence of six chronic diseases were still included in the final model, although these factors did not appear significant in the multivariable model, due to its strong association with cognitive decline based on previous literature. Certain noncategorical variables such as intake of fresh fruits or fruit juices, disability, and years of education were converted to categorical variables for easier administration. Table 1 lists the initial selection of questions for the screening tool.

\section{Calculation of sensitivity and specificity of the screening tool}

The odds ratio of the selected variable was converted into a simplified coefficient for convenience in scoring. Sensitivity and specificity were calculated using binary logistic regression on a subset of 493 subjects who were randomly selected. Sensitivity and specificity were calculated for each cut-off point (Table 2). Sensitivity and specificity were calculated using the following formulae:

Sensitivity: True positive/(true positive + falsenegative)

Specificity: True negatives/(true negative + falsepositive)

\section{Determination of predictive accuracy of TUA-WELLNESS tool}

Both predictive accuracy and concurrent validity were calculated on randomly selected 493 community dwelling older adults. Area under the receiver operating characteristic curve (AUC) was calculated to identify the predictive accuracy of the TUA-WELLNESS. AUC showed the effectiveness of the TUA-WELLNESS tool to screen for MCI among community dwelling older adults. Greater AUC curve indicated robustness of the screening tool in classifying cognitive decline. Youden's Index [(sensitivity + specificity $)-1]$ 
Table I Selection of questions for TUA-WELLNESS screening tool

\begin{tabular}{|c|c|c|}
\hline Parameters & OR & $P$-value \\
\hline $\begin{array}{l}\text { I. Are you having at least one of these chronic diseases (diabetes, hypertension, heart diseases, } \\
\text { stroke, chronic lung diseases, or cancer)? }\end{array}$ & 1.18 & $0.19^{a}$ \\
\hline 2. Are you still capable of having sexual relationship with your spouse? & $\mathrm{I} .14$ (if the answer is no) & 0.12 \\
\hline 3. What is your marital status? & 0.83 (if single) & 0.16 \\
\hline 4. What is the level of your blood sugar (low, normal, or high)? & 1.58 & 0.00 \\
\hline 5. What is the level of your blood cholesterol (normal or high)? & 1.78 & 0.00 \\
\hline 6. Do you have osteoarthritis? & 1.13 & 0.15 \\
\hline $\begin{array}{l}\text { 7. Do you indulge in simple mechanical repairing activities such as changing bulb or repairing tap } \\
\text { leakages? }\end{array}$ & 2.28 (if the answer is no) & 0.01 \\
\hline 8. Do you use modern gadgets such as smartphones or iPads? & 1.99 (if the answer is no) & 0.01 \\
\hline $\begin{array}{l}\text { 9. Do you practice calorie restriction through "Sunnah" fasting, vegetarianism, or restricting certain } \\
\text { foods for any occasions? }\end{array}$ & I.42 (if the answer is no) & 0.01 \\
\hline 10. Are you consuming fresh fruits or fresh fruit juices daily? & 0.95 (if the answer is yes) & 0.01 \\
\hline II. What is your education level? & 0.92 (if higher education level) & 0.00 \\
\hline 12. Are you having disability in doing daily routine or learning new task or socializing with others? & 1.02 & 0.01 \\
\hline 13. Are you having good social network? & 0.87 (if good) & 0.29 \\
\hline 14. What is your perception of your quality of life? & 0.87 (if good) & $0.56^{\mathrm{a}}$ \\
\hline 15. What is your perception of your health status? & I.I (if poor health) & $0.62^{\mathrm{a}}$ \\
\hline
\end{tabular}

Note: a Odds ratio for three questions obtained using chi-square.

Abbreviation: OR, odds ratio.

was calculated. Best cut-off point for the screening tool was chosen based on the highest Youden's Index and sensitivity value above $70 \%{ }^{28}$ Ninety-five percent confidence interval (CI) was calculated for each cut-off point (Table 2).

\section{Concurrent validity}

Concurrent validity for normally distributed variables was calculated using Pearson correlation. If the assumptions of normality were violated, Spearman's rho was used and 95\% CIs were calculated using the bias-corrected bootstrap method.

Concurrent validity was analyzed to determine the correlation between the score of the TUA-WELLNESS screening tool with scores on standard cognitive tests such as MMSE, Montreal cognitive assessment (MoCA), digit span, RAVLT, digit symbol, and visual reproduction test.

Table 2 AUC, sensitivity, specificity, and Youden's Index for possible cut-off points

\begin{tabular}{lllll}
\hline Cut-off & AUC $(\mathbf{9 5 \%} \mathbf{C I})$ & $\begin{array}{l}\text { Specificity } \\
\text { (\%) }\end{array}$ & $\begin{array}{l}\text { Sensitivity } \\
\mathbf{( \% )}\end{array}$ & $\begin{array}{l}\text { Youden's } \\
\text { Index }\end{array}$ \\
\hline$\geq 7$ & $0.84(0.78-0.90)$ & 76.2 & 74.2 & 0.50 \\
$\geq 8$ & $0.84(0.78-0.90)$ & 74.7 & 76.2 & 0.51 \\
$\geq 9$ & $0.84(0.78-0.90)$ & 74.2 & 76.2 & 0.50 \\
$\geq 10$ & $0.84(0.78-0.90)$ & 74.2 & 73.8 & 0.48 \\
$\geq 11$ & $0.84(0.78-0.90)$ & 73.4 & 83.3 & 0.57 \\
$\geq 12$ & $0.84(0.78-0.90)$ & 73.8 & 76.2 & 0.50 \\
$\geq 13$ & $0.84(0.78-0.90)$ & 74.7 & 76.2 & 0.51 \\
$\geq 14$ & $0.84(0.78-0.90)$ & 74.7 & 73.8 & 0.49 \\
\hline
\end{tabular}

Note: Cut-off $\geq 1 \mathrm{I}$ was chosen because it had the highest sensitivity (83.3\%) and Youden's Index (0.57).

Abbreviations: AUC, area under curve; $\mathrm{Cl}$, confidence interval.
Summary of statistical test used for this study is shown in Figure 1.

\section{Results}

The mean age of the respondents was $68.5 \pm 5.93$ years, and $50.3 \%$ of the participants were men and $49.7 \%$ women. Most of the respondents were able to read, write, and count $(92.3 \%)$ and were retired $(76.1 \%)$. The most commonly reported chronic disease was hypertension (50.4\%), followed by hyperlipidemia (32.0\%), diabetes (26.6\%), osteoarthritis (24.0\%), and cataract or glaucoma $(24.0 \%)$. The prevalence of MCI in this study was $16.0 \%$ as reported in an earlier study. ${ }^{29}$

The items in TUA-WELLNESS screening tool are listed in Table 3.

As listed in Table 1, the three questions related to health status, quality of life, and chronic diseases are not from OLR. These were chosen due to their association with good cognitive function.

Table 3 lists the 10 items in the TUA-WELLNESS screening tool. Item 7 was different for men and women. The final OLR model showed that mechanical repairing activities were protective against cognitive decline. However, this was not common among women. Thus, another question on frequency of reading or sewing was created for women. Reading and sewing were chosen based on their significance during univariate analysis. Similarly, item 8 was divided into two sections; Muslim subjects would answer the section on "Sunnah fasting", while non-Muslim subjects were required to answer the section on practicing calorie restriction based on respective beliefs. Items 5 (fruits/vegetables) 


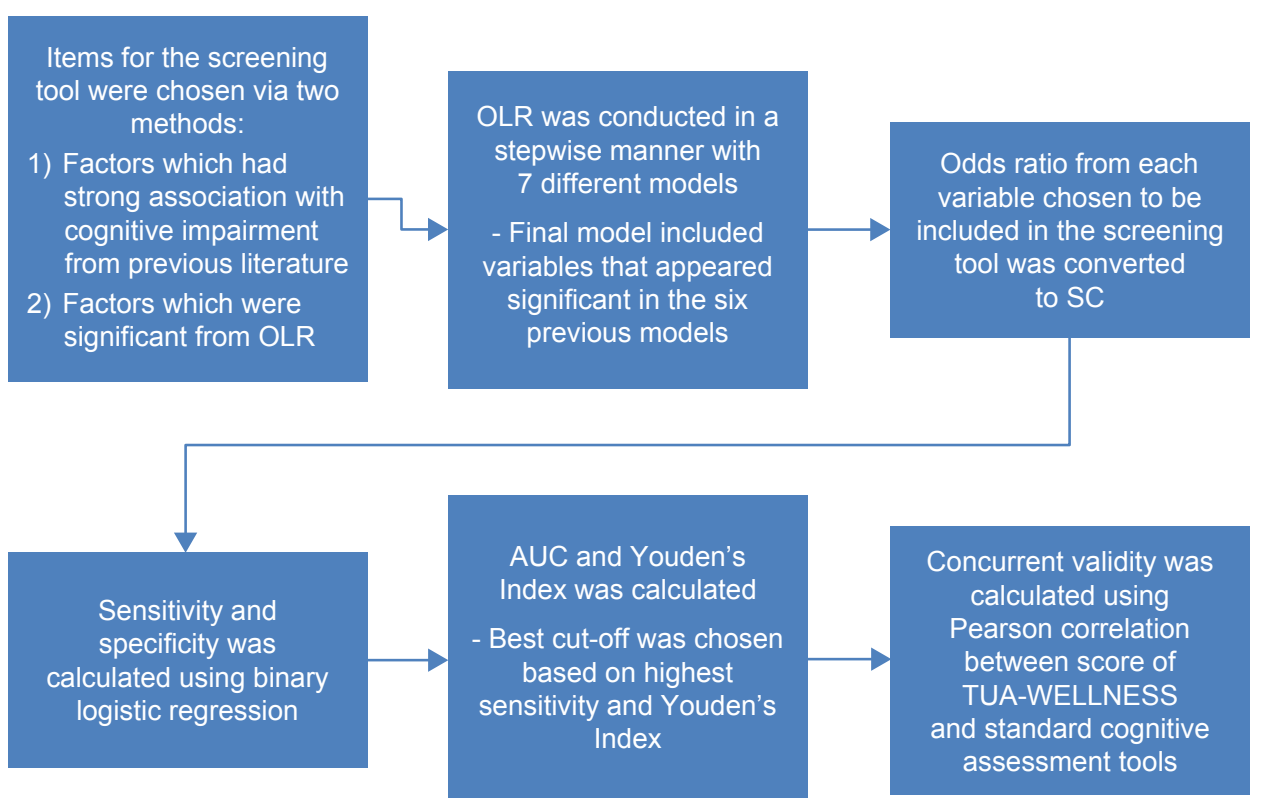

Figure I Summary of statistical analysis used in this study.

Abbreviations: OLR, ordinal logistic regression; SC, simplified coefficient; AUC, area under curve.

Table 3 Final Selection of Questions for TUA-WELLNESS

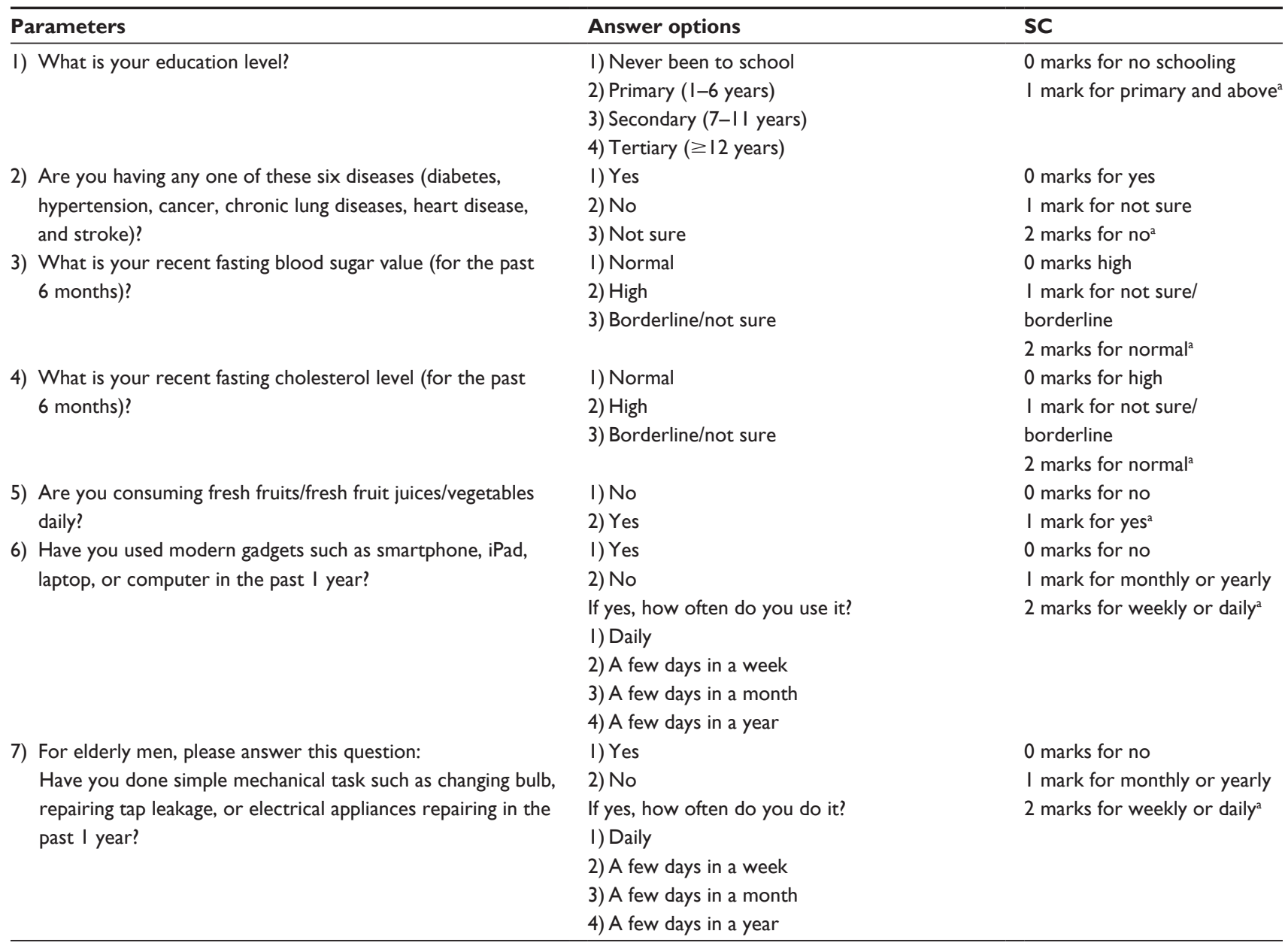

(Continued) 
Table 3 (Continued)

\begin{tabular}{|c|c|c|c|}
\hline \multicolumn{2}{|c|}{ Parameters } & Answer options & \multirow{2}{*}{$\begin{array}{l}\text { SC } \\
0 \text { marks for no }\end{array}$} \\
\hline & For elderly women, please answer this question: & I) Yes & \\
\hline & Did you read story books/newspaper/religious book/ & 2) No & I mark for monthly or yearly \\
\hline & magazines or perform sewing activities in the past I year? & If yes, how often you use it? & 2 marks for weekly or daily ${ }^{a}$ \\
\hline & & I) Daily & \\
\hline & & 2) A few days in a week & \\
\hline & & 3) A few days in a month & \\
\hline & & 4) A few days in a year & \\
\hline \multirow{8}{*}{ 8) } & For older adults who are Muslim, please answer this question. & I) Yes & 0 marks for no \\
\hline & Did you perform calorie restriction in the form of "Sunnah" & 2) No & I mark for sometimes \\
\hline & fasting for the past I month? & 3) Sometimes & 2 marks for yes ${ }^{\mathrm{a}}$ \\
\hline & For older adults who are non-Muslim, & & \\
\hline & please answer this question. & & \\
\hline & Did you perform calorie restriction based on your religion & & \\
\hline & (not eating and drinking, not eating but only drinking or & & \\
\hline & practicing healthy vegetarian diet for few days a week?) & & \\
\hline \multirow{14}{*}{ 9) } & Are you having any of these problems? & I) Difficulty to stand for $30 \mathrm{~min} /$ walk for I km/ & 0 marks if any items from I to \\
\hline & (you may choose more than I answer) & bathe/dress & 5 is/are chosen \\
\hline & & 2) Difficulty to manage household & I mark if item 6 is chosen ${ }^{a}$ \\
\hline & & responsibilities such as gardening or & \\
\hline & & purchasing household items & \\
\hline & & 3) Difficulty to learn new task such as & \\
\hline & & learning to use microwave, learning to use & \\
\hline & & smartphone, learning to sew, or learning to & \\
\hline & & go to new place & \\
\hline & & 4) Difficulty to focus on a specific task for at & \\
\hline & & least 10 minutes & \\
\hline & & 5) Difficulty to communicate with new people & \\
\hline & & or maintaining friendship & \\
\hline & & 6) Not having any of the listed problem & \\
\hline \multirow[t]{4}{*}{ 10) } & Are you satisfied with your current quality of life and health & I) Yes & 0 marks for no \\
\hline & status? & 2) No & I mark for not sure \\
\hline & & 3) Not sure & 2 marks for yes ${ }^{\mathrm{a}}$ \\
\hline & & Total marks & 17 \\
\hline
\end{tabular}

Notes: aSimplified coefficient refers to the highest score for each item. The higher the score, the lower the risk of $\mathrm{MCl}$.

Abbreviations: SC, simplified coefficient; $\mathrm{MCl}$, mild cognitive impairment.

and 10 (quality of life/health status) consisted of more than one component. This was done to form a screening tool with lesser items for convenience of older adults.

Cut-off 11 was chosen because it had the highest sensitivity (83.3\%) and Youden's Index (0.57). AUC value for TUA-WELLNESS was 0.84 , indicating very good discriminating power. The total score for this tool was 17 , and higher scores indicated lower risk of MCI (Table 3).

As listed in Table 4, concurrent validity between TUAWELLNESS and other standard cognitive assessment tools have shown significantly weak to moderately positive correlation. Meanwhile, for normally distributed RAVLT score, Pearson's correlation was 0.40 (95\% CI: $0.30-0.49, P<0.001)$.

\section{Discussion}

This study team has developed a ten-item questionnaire which was successfully used as a screening tool to identify elderly at risk of MCI. Cut-off point 11 was chosen as the suitable cut-off point because it had the highest Youden's Index and sensitivity values. Apart from that, AUC of 0.84 was excellent and enabled us to distinguish older adults with cognitive impairment. Hosmer and Lemeshow ${ }^{30}$ have

Table 4 Concurrent validity between TUA-WELLNESS and other cognitive assessment tools

\begin{tabular}{llll}
\hline Variables & $\begin{array}{l}\text { Correlation } \\
\text { coefficient }\end{array}$ & $\boldsymbol{P}$-value* & BCa 95\% Cl \\
\hline MMSE & 0.24 & 0.000 & $0.14-0.34$ \\
MoCA & 0.35 & 0.000 & $0.27-0.43$ \\
Digit symbol & 0.38 & 0.000 & $0.29-0.47$ \\
Visual reproduction I & 0.30 & 0.000 & $0.19-0.40$ \\
Visual reproduction II & 0.27 & 0.000 & $0.18-0.39$ \\
\hline
\end{tabular}

Notes: $* P<0.01$, significant using Spearman's rho. ${ }^{\text {aBias-corrected bootstrap }}$ method.

Abbreviations: $\mathrm{Cl}$, confidence interval; MMSE, Mini Mental State Examination; MoCA, Montreal cognitive assessment; BCa, bias-corrected and accelerated method. 
reported that an AUC value of $<0.7$ is considered poor, $0.7-0.8$ acceptable, $0.8-0.9$ excellent, and $0.9-1.0$ is outstanding discrimination.

TUA-WELLNESS tool is a good screening tool because it is simple, can be completed by older adults without assistance, and enables self-calculation of score. It meets the criteria of an appropriate tool for screening purpose ${ }^{31}$ Older adults and their caregivers are able to know their risk of MCI by summing the scores listed at the end of each box. Hence, they may immediately identify their risk of MCI. Older adults who persistently obtain low score in TUA-WELLNESS have to perform some lifestyle modifications, which include keeping blood glucose and cholesterol levels in the normal range, frequently engaging in mentally demanding task such as exploring modern gadgets such as smartphones and iPads, practicing calorie restriction via occasional fasting, and increasing intake of fresh fruits and vegetables. Although poor intake of vegetables is not a risk factor of MCI in our study, it has been included in the screening tool following previous literature, which has shown protective effects of higher vegetables intake against both cognitive decline and dementia. ${ }^{32}$

Questions related to quality of life, self-rated health, and presence of chronic diseases are part of the tool despite their being nonsignificant. Montejo et $\mathrm{al}^{33}$ (2012) have demonstrated that quality of life is an important predictor of memory complaint among 1,637 noninstitutionalized older adults. Besides that, Hamid et $\mathrm{al}^{14}$ have proposed that healthy or optimal aging can be achieved by absence of six chronic diseases (hypertension, diabetes, heart disease, chronic lung diseases, cancer, and stroke) and superior satisfaction in health status. Pimenta et $\mathrm{al}^{34}$ have reported that chronic diseases among older adults increased the risk of cognitive decline, functional impairment, and affected quality of life. Older adults with dementia usually present with multimorbidities as compared to elderly with no cognitive impairment.

TUA-WELLNESS is not for screening for dementia and is not suitable to be used for diagnostic purpose. Sensitivity and specificity of the TUA-WELNESS is acceptable and almost similar with other available screening tools for MCI. In a population-based study among older adults in the United Kingdom, prevalence of MCI was found to be $20 \%$ using Petersen's criteria, and MoCA was used as cognitive assessment tool. Sensitivity was in the range of $80 \%-100 \%$, while specificity is within $50 \%-76 \%$. $^{35}$

The available assessments for MCI such as MMSE, MoCA, or CDT have emphasized only cognitive function, but fail to capture other risk factors associated with MCI, such as comorbidities, consumption of fruits and vegetables, and engaging in cognitive stimulating tasks. Hence, TUA-WELLNESS is a comprehensive screening tool specifically for detecting MCI, and the items included in TUA-WELLNESS tool have been proven to be predictors of MCI in previous studies. However, this study has certain limitations. TUA-WELLNESS is not applicable for diagnostic purpose. An individual scoring below 11 for the tool should not be confirmed as having MCI but needs to be informed for further in-depth cognitive assessment. Besides, validation of TUA-WELLNESS is still ongoing, and thus is not reported in this paper.

In conclusion, TUA-WELLNESS screening tool has managed to embrace major risk factors of MCI among Malaysian older adults. This tool has an excellent AUC, Youden's Index, and sensitivity values for identifying elderly at risk of MCI. However, this tool is only suitable for basic MCI risk screening purpose. Older adults with higher risk of MCI, assessed using this tool, should be motivated to make lifestyle changes to preserve mental health.

\section{Compliance with ethical standard}

This study, which involved humans, meets the ethical guidelines of the Universiti Kebangsaan Malaysia Research Ethics Committee and the 1964 Helsinki Declaration and its later amendments or comparable ethical standards. Informed consent was obtained from all participants.

\section{Acknowledgments}

The authors thank Ministry of Education Malaysia for funding the study through Long-term Research Grant Scheme (LRGS) (LRGS/BU/2012/UKM-UKM/K/01). We appreciate the contribution and hard work of all coresearchers, staffs, fieldworkers, local council, and respondents.

\section{Disclosure}

The authors report no conflicts of interest in this work.

\section{References}

1. Albert MS, DeKosky ST, Dickson D, et al. The diagnosis of mild cognitive impairment due to Alzheimer's disease: recommendations from the National Institute on Aging Alzheimer's Association workgroups on diagnostic guidelines for Alzheimer's disease. Alzheimers Dement. 2011;7(3):270-279.

2. Ganguli M, Fu B, Snitz BE, Chang CCH. Mild cognitive impairment: incidence and vascular risk factors in a population-based cohort. Neurology. 2013;80:2112-2120.

3. Mol M, Carpay M, Ramakers I, Rozendaal N, Verhey F, Jolles J. The effect of perceived forgetfulness on quality of life in older adults: a qualitative review. Int J Geriatr Psychiatry. 2007;22:393-400.

4. Sun Q, Townsend MK, Okereke OI, Franco OH, Hu FB, Grodstein F. Physical activity at mid-life in relation to successful survival in women at age 70 years and older. Arch Intern Med. 2010;170:194-201. 
5. Etgen T, Sander D, Bickel H, Forstl H. Mild cognitive impairment: the importance of modifiable risk factors. Dtsch Arztebl Int. 2011;108: 743-750.

6. Belleville S, Clement F, Mellah S, Gilbert B, Fontaine F, Gauthier S. Training-related brain plasticity in subjects at risk of developing Alzheimer's disease. Brain. 2011;134:1623-1634.

7. DeWeerdt S. Prevention: activity is the best medicine. Nature. 2011; 475(7355):16-17.

8. Cullen B, O'Neill B, Evans JJ, Coen RF, Lawlor BA. A review of screening tests for cognitive impairment. J Neurol Neurosurg Psychiatry. 2007;78:790-799.

9. Nishiwaki Y, Breeze E, Smeeth L, Bulpitt CJ, Peters R, Fletcher AE. Validity of the clock drawing test as a screening tool for cognitive impairment in the elderly. Am J Epidemiol. 2004;160:797-807.

10. Cordell CB, Borson S, Boustani M, et al. Alzheimer's Association recommendations for operationalizing the detection of cognitive impairment during the Medicare Annual Wellness Visit in a primary care setting. Alzheimers Dement. 2013;9(2):141-150.

11. Anstey KJ, Cherbuin N, Herath PM, et al. A self-report risk index to predict occurrence of dementia in three independent cohorts of older adults: the ANU-ADRI. PLoS One. 2014;9(1):e86141.

12. Ministry of Health Malaysia, Malaysian Psychiatric Association, Academy of Medicine Malaysia, Malaysian Society of Neurosciences. Clinical Practice Guidelines. Management of Dementia. 2nd ed. Putrajaya, Malaysia: Ministry of Health Malaysia; 2009.

13. Ibrahim N, Shohaimi S, Chong HT, Abdul Rahman AH, Razali R, Ebernezer E. Validation study of the Mini-Mental State Examination in a Malay-speaking elderly population in Malaysia. Demet Geriatic Cogn Disord. 2009;27:247-253.

14. Hamid TA, Yadollah AM, Rahimah I. Predictors and prevalence of successful aging among older Malaysians. Gerontology. 2012;58(4): 366-370.

15. Petersen RC, Caracciolo B, Brayne C, Gauthier S, Jelic V, Fratiglioni L. Mild cognitive impairment: a concept in evolution. J Intern Med. 2014; 275:214-228.

16. Lee LK, Shahar S, Chin AV, Mohd Yusoff NA, Rajab NF, Abdul Aziz S. Prevalence of gender disparities and predictors affecting the occurrence of mild cognitive impairment (MCI). Arch Gerontol Geriatr. 2012;54:185-191.

17. Folstein MF, Folstein SE, McHugh PR. Mini-Mental State: a practical method for grading the cognitive state of patients for the clinician. J Psychiatr Res. 1975;12:189-198.

18. Wechsler D. Wechsler Adult Intelligence Scale-III. San Antonio, TX: The Psychological Corporation; 1997.

19. Strauss E, Sherman EM, Spreen O. A Compendium of Neuropsychological Tests: Administration, Norms, and Commentary. New York, NY: Oxford University Press; 2006.

20. Sherbourne CD, Stewart AL. The MOS social support survey. Soc Sci Med. 1991;32(6):705-714.
21. Eysenck HJ, Eysenck SBG. Manual for the Eysenck Personality Questionnaire - Revised. San Diego, CA: Educational and Industrial Testing Service; 1992.

22. Lubben J, Blozik E, Gillmann G, et al. Performance of an abbreviated version of the lubben social network scale among three European community-dwelling older adult populations. Gerontologist. 2006;46(4): 503-513.

23. Andrews G, Kemp A, Sunderland M, von Korff M, Ustun TB. Normative Data for the 12 Item WHO Disability Assessment Schedule 2.0. PLoS One. 2009;4(12):8343-8348.

24. Hultsch DF, Hertzog C, Small BJ, Dixon RA. Use it or lose it: engaged lifestyle as a buffer of cognitive decline in aging? Psychol Aging. $1999 ; 2: 245-263$

25. WHO. Obesity: preventing and managing the global epidemic. Report of a WHO Consultation on Obesity. Geneva, Switzerland: World Health Organization; 1998.

26. IDF. The IDF Consensus Worldwide Definition of the Metabolic Syndrome. Brussels, Belgium: International Diabetes Federation; 2006.

27. Shahar S, Earland J, Abdulrahman S. Validation of a dietary history questionnaire against a 7-D weighed record for estimating nutrient intake among rural elderly Malays. Malays J Nutr. 2000;6(1):33-44.

28. Russell M, Hill KD, Blackberry I, Day LM, Dharmage SC. The reliability and predictive accuracy of the falls risk for older people in the community assessment (FROP-Com) tool. Age and Ageing. 2008:37;634-639.

29. Shahar S, Omar A, Vanoh D, et al. Approaches in methodology for population-based longitudinal study on neuroprotective model for healthy longevity (TUA) among Malaysia older adults. Aging Clin Exp Res. December 15, 2015.

30. Hosmer DW Jr, Lemeshow S. Applied Logistic Regression. New York, NY: John Wiley \& Sons; 2004.

31. Elmore MF, Wagner DR, Knoll DM, et al. Developing an effective adult nutrition screening tool for a community hospital. J Am Diet Assoc. 1994; 94:113-118

32. Loef M, Walach H. Fruit, vegetables and prevention of cognitive decline or dementia: a systematic review of cohort studies. J Nutr Health Aging. 2012;16(7):626-630.

33. Montejo P, Montenegro M, Fernandez MA, Maestu F. Memory complaints in the elderly: quality of life and daily living activities A population based study. Arch Gerontol Geriatr. 2012;54:298-304.

34. Pimenta FAP, Bicalho MAC, Romano-Silva MA, de Moraes EN, de Rezende NA. Chronic diseases, cognition, functional decline, and the Charlson index in elderly people with dementia. Rev Assoc Med Bras. 2013;59(4):326-334.

35. Markwick A, Zamboni G, de Jager CA. Profiles of cognitive subtest impairment in the Montreal Cognitive Assessment (MoCA) in a research cohort with normal Mini-Mental State Examination (MMSE) scores J Clin Exp Neuropsychol. 2012;34(7):750-757.
Clinical Interventions in Aging

\section{Publish your work in this journal}

Clinical Interventions in Aging is an international, peer-reviewed journal focusing on evidence-based reports on the value or lack thereof of treatments intended to prevent or delay the onset of maladaptive correlates of aging in human beings. This journal is indexed on PubMed Central, MedLine,

\section{Dovepress}

CAS, Scopus and the Elsevier Bibliographic databases. The manuscript management system is completely online and includes a very quick and fair peer-review system, which is all easy to use. Visit http://www.dovepress. com/testimonials.php to read real quotes from published authors. 